\title{
A organização da unidade africana como expressão do projeto político continental no pós-independência: disputa e reivindicações
}

\begin{abstract}
Márcia Fernandes ${ }^{1}$
Resumo: O objetivo desse artigo é destacar o papel da agência africana nos âmbitos regional e internacional no contexto das primeiras independências do continente para compreender seus objetivos e apresentar uma resposta à ideia simplista de que a África está condenada a ser uma grande vítima das injustiças pelas quais passou. Nesse sentido, a Organização da Unidade Africana (OUA) será o objeto de estudo desse artigo tendo em vista que sua criação foi, no contexto considerado, a primeira resposta dos países africanos aos problemas locais e internacionais que estavam vivenciando. A análise das cúpulas da organização de 1963 a 1976 será realizada considerando não apenas os grandes objetivos comuns entre os seus membros, mas também as suas disputas de interesses e, principalmente, o embate entre Egito e Gana pela liderança do continente. As fontes pesquisadas foram as declarações da OUA e a bibliografia especializada no assunto que discute o contexto no qual as cúpulas se realizaram, bem como as principais questões políticas africanas e internacionais da época. Por fim, conclui-se que a OUA foi capaz de mostrar para os demais países do mundo que a agência africana não poderia mais ser negligenciada no sistema internacional devido à relevância política do continente.
\end{abstract}

Palavras-chave: África; Egito; Gana; Organização da Unidade Africana.

\begin{abstract}
The purpose of this article is to analyze the role of the African agency in the regional and international levels in the context of the first independence to understand your goals and present a response to the simplistic idea that Africa is bound to be a major victim of injustices through which it passed. In this sense, the Organization of African Unity (OAU) will be the subject matter of this article given that its creation was, in the context analyzed, the first answer of African countries to the local and international problems they were experiencing. The analysis of the summits from 1963 to 1976 will be carried out considering not only the broad common goals among its members, but also their disputed interests and especially the clash between Egypt and Ghana for the leadership of the continent. The sources researched are the declarations of the OAU and the specialized bibliography on the subject that discusses the context in which the summits were held and the main African and international political issues of the time. Finally, it is concluded that the OAU was able to show to the rest of the world that African agency could no longer be neglected in the international system due to the political importance of the continent.
\end{abstract}

Keywords: Africa; Egypt; Ghana; Organization of African Unity.

1Márcia de Paiva Fernandes é Bacharel em Relações Internacionais pela PUC Minas e atualmente é aluna do Mestrado em Ciência Política no Instituto de Filosofia e Ciências Humanas da Universidade Estadual de Campinas. Email: $\underline{\text { mp.fernandes@hotmail.com . }}$ 


\section{Introdução}

O senso comum sobre a África parece limitar a análise do continente aos seus problemas internos e considerar que sua inserção internacional é pautada pela busca de soluções para eles. Essa visão ignora uma série de questões, como as tentativas promovidas pelos países africanos de adotar uma política autônoma de inserção internacional, as disputas entre eles pela liderança do continente, os líderes políticos africanos que contribuíram com importantes debates internacionais e o peso político que os países africanos possuem. Tomando como estudo de caso a Organização da Unidade Africana (OUA), os seus objetivos, as suas denúncias e as suas disputas internas pela liderança da África, são exemplos claros de que as análises de política internacional são deficientes quando descartam a relevância política dos países africanos.

Nesse sentido, o objetivo desse artigo é apresentar a forma pela qual a agência africana se manifestou no contexto das primeiras independências no continente e quais eram os seus propósitos. Parte-se do pressuposto de que a OUA foi estabelecida com o objetivo geral de eliminar o domínio colonial da África para proporcionar ao continente a autonomia necessária para lidar com seus problemas internos e para buscar um novo modelo de inserção internacional que lhe desse a devida importância. Por outro lado, tal objetivo geral não eliminou as disputas no âmbito da OUA, principalmente entre Egito e Gana, e tampouco os choques de interesses entre as elites políticas a despeito das experiências comuns vivenciadas pelos seus países.

A estrutura do artigo está dividida da seguinte forma: uma grande seção onde serão abordadas questões como a formação da OUA, a disputa entre Egito e Gana e a análise das declarações da organização. Ao longo dessa seção serão introduzidas algumas constatações sobre temas que ajudam a explicar as questões mencionadas, como o debate sobre a identidade, a ênfase na agência dos países da OUA e o modo como suas elites políticas lidaram com isso. Posteriormente, as considerações finais apresentarão uma breve análise das questões discutidas. As fontes utilizadas no artigo são as declarações das cúpulas de chefe de Estado anuais da OUA de 1963 a 1976, mas ele também faz uso da bibliografia especializada nos temas discutidos. O recorte temporal das cúpulas foi feito para analisar as declarações no período de conquista das independências nos anos 1960; para analisar o modo como a OUA lidou com o conflito entre Egito e Israel; e para acompanhar a disputa entre aquele país e Gana. Embora Kwame Nkrumah tenha sido deposto da presidência em 1966 e Gamal Abdel Nasser tenha falecido em 1970, a análise das declarações das cúpulas até alguns anos após o fim do governo de cada um deles permite 
acompanhar o modo como os países africanos lidaram com as questões defendidas pelos dois presidentes após o fim de seus governos.

\section{A organização da Unidade Africana: espaço de disputas e de reivindicações}

Estabelecida em 1963, a OUA ${ }^{2}$ foi o resultado de um processo de negociação entre os líderes dos países africanos independentes naquele ano para que suas diferenças políticas fossem apaziguadas em prol do objetivo comum de extirpar o colonialismo da África. Antes do estabelecimento da organização, os países africanos estavam divididos entre o Grupo de Casablanca e o Grupo de Monróvia. O primeiro deles, formado pela República Árabe Unida (RAU) - nome dado à união política entre Egito e Síria que existiu de 1958 a 1961 sob a presidência de Gamal Abdel Nasser -, Gana, Guiné, Líbia, Mali e Marrocos, era considerado mais radical por ser favorável à integração política entre os Estados africanos. Os chefes de Estado dos países que o compunham eram em sua maioria socialistas, Pan-africanistas e engajados no Movimento dos Não Alinhados $^{3}$ (MNA), defendendo o desenvolvimento econômico centralizado, o estabelecimento de um sistema de defesa comum no continente e a valorização da cultura africana (ASANTE; CHANAIWA, 2010).

Já o Grupo de Monróvia, formado pelas antigas colônias francesas além de Nigéria, Etiópia, Libéria, Serra Leoa, Somália, República do Congo e Tunísia, defendia uma integração mais flexível entre os países africanos que não gerasse perdas de soberania e que permitisse a participação voluntária em termos culturais e econômicos. Esse grupo enxergava no discurso integracionista do Grupo de Casablanca uma tentativa de influenciar a política interna dos demais países africanos e, além do mais, defendia a manutenção das fronteiras nacionais conforme elas se encontravam no momento da independência para evitar disputas, bem como a continuidade das relações com as antigas metrópoles (ASANTE; CHANAIWA, 2010).

O objetivo comum dentro e entre os dois grupos de acabar com o colonialismo na África permitiu que eles se reunissem em 1963 em Addis Abeba a fim de resolver as principais divergências entre eles e estabelecer um espaço de cooperação interafricana. O encontro na capital etíope resultou na Carta Manifesto pela Unidade Africana que criou a OUA cujos princípios

2 A OUA existiu até 2001 quando foi substituída pela União Africana a partir do argumento de que o contexto que motivou a criação da antiga organização havia se transformado muito e que, portanto, um novo arranjo institucional era necessário para lidar com as questões atuais (DÖPCKE, 2002).

3 Movimento lançado na Conferência de Bandung em 1955, organizada pelos presidentes da Iugoslávia, da Índia e da Indonésia, na qual os países que dela participaram adotaram uma posição de neutralidade positiva na Guerra Fria, ou seja, a possibilidade de negociar com os dois blocos em conflito de acordo com interesses internos (WESTERN, 1997). 
norteadores eram buscar a independência política dos países africanos, apoiar os movimentos de libertação e formar uma posição unânime no âmbito da Organização das Nações Unidas (ONU) (ASANTE; CHANAIWA, 2010; KODJO; CHANAIWA, 2010).

A partir da observação das divisões políticas na África que resultaram na formação de dois grupos distintos, pode-se afirmar que as elites políticas do continente travaram uma disputa entre si ao defenderem propostas distintas sobre os melhores rumos para os países africanos. O fato deles terem vivenciado experiências comuns - colonização e escravidão, por exemplo - não significou a adoção de políticas homogêneas a partir da conquista das primeiras independências (APPIAH, 1997). Ao contrário, conforme os regimes coloniais foram chegando ao fim, as elites políticas africanas tiveram que encarar a missão de construir uma nação para os Estados que herdaram e lidar com os diferentes interesses dos grupos internos a respeito dos rumos que deveriam ser adotados (FALOLA, 2001). Destarte, as lideranças políticas africanas discordaram e competiram entre si por recursos políticos e econômicos, assim como ocorre entre líderes de outros continentes. Partir do pressuposto de que os interesses dos países africanos são comuns em todas as áreas devido ao compartilhamento de algumas experiências significa desconsiderar a pluralidade política e social que caracteriza a África (APPIAH, 1997).

Em se tratando de disputas entre lideranças no continente no âmbito da OUA, nenhuma delas foi tão evidente quanto a que ocorreu entre o egípcio Nasser e Kwame Nkrumah, primeiro presidente de Gana. Embora ambos pertencessem ao Grupo de Casablanca, isso não impediu o surgimento de uma rivalidade entre eles na medida em que lançaram seus países como líderes dos demais na busca pela independência, na extirpação do imperialismo e na promoção de uma inserção internacional mais favorável à África. Usando diferentes argumentos e mobilizando a OUA para atender interesses nacionais específicos, o embate entre Nasser e Nkrumah evidenciou não apenas que o Egito possuía políticas voltadas para a África, mas também que ambos reconheciam a importância política cada vez maior do continente a partir das conquistas das independências. Essa disputa pela África entre países africanos e as posteriores declarações da própria OUA eram um sinal claro para o mundo desenvolvido de que já não era viável negligenciar o peso político do continente.

\section{A disputa pela África entre Egito e Gana: interesses, estratégias e discursos}

Antes de abordar a política de cada um dos presidentes para a África e a disputa entre eles, é necessário fazer uma breve justificativa de considerar o Egito como um importante país africano. A 
clássica afirmação na literatura acadêmica sobre a posição geográfica estratégica do país no cruzamento entre o Oriente Médio e o Mediterrâneo, parece muitas vezes ignorar o seu pertencimento ao continente africano. Afirmar que o Egito está localizado entre duas regiões contribui para retirá-lo simbolicamente da África e para não atribuir grande importância aos interesses desse país no continente (HATEM, 2009).

A literatura sobre a África muitas vezes separa os países localizados no norte do continente do restante de seu território, criando a impressão de que eles são muito diferentes dos demais e que não podem ser classificados de forma geral como africanos, mas sim como árabes ou mediterrâneos. É importante considerar, por outro lado, que as divisões regionais da África são designações externas recentes. Grande parte da separação acadêmica entre o Norte da África do restante do continente deve-se à emergência dos Estados Unidos da América (EUA) como potência internacional após a Guerra Fria e do seu desejo de minar a influência dos antigos poderes coloniais na África. Para tanto, os responsáveis pela formulação de sua política externa substituíram o nome do Oriente Próximo para Oriente Médio e separaram o Norte da África do restante do continente. Os acadêmicos aderiram a essa separação estratégica e passaram a produzir conhecimento especializado para cada região com poucas conexões entre si $^{4}$ (HATEM, 2009).

O que essa separação artificial desconsidera é que as interações comerciais, culturais e religiosas entre o Norte da África e o restante do continente datam do período inicial da expansão do Islã no século VIII, quando mercadores muçulmanos viajaram para os países africanos ou se estabeleceram neles. Como resultado desse contato, a religião islâmica e a língua árabe se disseminaram na África em um ritmo crescente, não encontrando em sua diversidade étnica ou em barreiras geográficas limites para sua expansão (DOBRONRAVINE, 2003). Nesse sentido, não se pode justificar a atual separação política e acadêmica do continente em termos raciais - já que o Norte da África também é habitado por negros - ou naturais, tendo em vista que o deserto do Saara não foi um obstáculo para o contato entre os povos africanos: conforme a concepção de Fernand Braudel apresentada por Thornton (2000), o Saara foi um espaço que conectou diferentes culturas e que criou espaços interconectados. Portanto, considerar o Norte da África como uma região à parte do restante do continente significa descartar o histórico de relações e de influência mútua entre os

4 Essa afirmação não desqualifica divisões no continente que possam existir na percepção dos próprios africanos ou exime os europeus de também terem dividido regionalmente a África. O seu objetivo é, na verdade, evidenciar que tanto no contexto internacional mais recente quanto entre grande parte dos acadêmicos, a tendência corrente é separar o Norte da África do restante do continente e que isso também é um resultado da influência estadunidense na política internacional: ao criar departamentos e agências que abordam as questões políticas dessa região como diferentes e desconectadas das demais, os centros de pesquisa, em sua maioria financiados pelo governo, aderiram à essa separação realizada pelos policimakers em sua abordagem para a África (HATEM, 2009). 
países africanos que, por seu turno, se fortaleceu ainda mais nas décadas de 1950 e 1960 quando muitos deles começaram a conquistar a sua independência (AKINSANYA, 1976).

No caso do Egito, sua independência foi reconhecida em 1922, mas o país permaneceu como um protetorado britânico até 1952, ano em que o Clube dos Oficiais Livres, liderado pelo General Naguib e pelo Coronel Nasser, destituiu a monarquia, expulsou as tropas britânicas e estabeleceu a República Árabe do Egito. A partir de 1956, Nasser assumiu a presidência do país e se tornou um dos líderes mais importantes no mundo discursando contra o imperialismo e projetando-se como o porta-voz dos países do Terceiro Mundo (WESTERN, 1997).

Com o objetivo de transformar a política e a sociedade de seu país, Nasser definiu no seu texto A Filosofia da Revolução os círculos concêntricos nos quais o Egito se encontrava, a saber, o árabe, o islâmico e o africano. O primeiro círculo foi considerado por Nasser como o mais importante devido à proximidade do Egito com o Oriente Médio e às profundas conexões culturais, históricas e sociais entre ambos, fazendo com que o país fosse sensível aos eventos que aconteciam naquela região. Em relação ao círculo religioso, o presidente egípcio afirmou que ele estava conectado com o círculo árabe e atribuiu ao Cairo um papel central no desenvolvimento e na disseminação do Islã (NASSER, 1959).

Em se tratando da África, embora Nasser tenha considerado o continente como um dos círculos concêntricos dentro do qual o Egito se localizava, ele o fez de uma maneira que afirmou a superioridade do país e o seu papel como líder do continente. Desse modo, enquanto denunciava o colonialismo na África, Nasser atribuiu ao Egito o papel de ajudar o continente a se libertar e até mesmo de civilizá-lo. O seguinte trecho de A Filosofia da Revolução demonstra a visão do líder egípcio sobre a África:

[...] Se nós dirigirmos nossa atenção para [...] o círculo do continente da África, eu diria, sem exageros, que nós não podemos, de qualquer maneira, ficar de fora, mesmo se nós quisermos, da sanguinária e terrível luta que assola o coração da África entre cinco milhões de brancos e duzentos milhões de africanos. Nós não podemos fazer isso por uma razão principal e clara, a saber, porque nós estamos na África. Os povos da África continuarão a olhar para nós, que guardamos o portão nordeste do continente e que somos o seu elo com $o$ mundo externo. Nós não podemos, sob qualquer condição, abandonar nossa responsabilidade em ajudar, de qualquer modo possivel, a disseminar a luz e a civilização nas partes mais distantes daquelas selvas virgens. (NASSER, 1959, p. 74-76, tradução nossa, grifo nosso) $)^{5}$.

5 If we direct our attention after that to the [...] continent of Africa, I would say, without exaggeration, that we cannot, in any way, stand aside, even if we wish to, away from the sanguinary and dreadful struggle now raging in the heart of Africa between five million whites and two hundred million Africans. We cannot do so for one principal and clear reason, namely that we are in Africa. The people of Africa will continue to look up to us, who guard the northern gate of the continent and who are its connecting link with the world outside. We cannot, under any condition, relinquish our responsibility in helping, in every way possible, in diffusing the light and civilization into 
Desse modo, Nasser negou uma ligação mais profunda entre o Egito e a África ao atribuí-la apenas a fatores geográficos e políticos, não destacando os vínculos culturais entre ambos. Nesse sentido, o presidente egípcio reconheceu que, mesmo que o seu país se localizasse na África, existiam diferenças entre o Egito e os demais países africanos. Entretanto, Nasser conseguiu contornar essas diferenças para se lançar como uma liderança continental na luta contra o imperialismo (TAGELDIN, 2014).

É preciso destacar a importância dessa separação realizada por Nasser entre três círculos concêntricos. Para além do fato de afirmar que o Egito era mais árabe do que africano, Nasser restringiu a identidade do primeiro círculo à ideia de um povo árabe, e não da língua árabe. Ao fazê-lo, ele excluiu desse círculo todos os falantes do idioma que se situavam fora da região do Oriente Médio, ou seja, ele não apenas barrou a identificação do Egito com a África, mas também lançou a ideia de que a identidade árabe não cabia aos africanos que falam a língua árabe e/ou aos muçulmanos do continente. Embora os povos africanos possuíam sua própria identidade muito antes da chegada do Islã no continente e considerando também que nem todo muçulmano é árabe, é possível perceber uma manipulação dos elementos definidores da identidade egípcia realizada por Nasser com o intuito de bloquear uma aproximação maior com a África que poderia ocorrer em virtude da presença do Islã e da língua árabe no continente. Tal manipulação pode ser observada na vinculação dos círculos árabe e muçulmano ao Oriente Médio realizada pelo presidente egípcio, entretanto, como ele mesmo afirmou, não era possível negar a localização do Egito na África e, a partir disso, foi necessário adotar políticas para os seus interesses ${ }^{6}$ no continente (TAGELDIN, 2014). Através de sua atuação na OUA, Nasser buscou, dessa forma, projetar a sua liderança, mas o seu protagonismo encontrou em Kwame Nkrumah um competidor à altura.

Primeiro presidente de Gana após a conquista da independência, Nkrumah foi, ao lado de Nasser, um dos maiores líderes africanos e uma das principais vozes contra o colonialismo, o imperialismo e a favor da integração africana. Na condição de um dos maiores defensores do Movimento Pan-africanista, Nkrumah foi capaz de mobilizar não apenas os Estados africanos já independentes, mas também os movimentos de libertação nas colônias remanescentes, lançando Gana como uma competidora do Egito na medida em ela também desejava liderar o continente na

the farthest parts of that virgin jungles.

6 Um dos interesses do Egito na África está ligado à sua dependência do rio Nilo para a subsistência de sua população e para a agricultura. O Egito tem mantido relações desde a época de Nasser até a atualidade com os países atravessados pelo Nilo, principalmente com Uganda, Sudão e Etiópia, para evitar que eles diminuam a quantidade de água que chega ao país através de desvios para a agricultura ou de construções de hidrelétricas, por exemplo (SOUARE, 2008). 
sua luta pela independência política e econômica (KODJO; CHANAIWA, 2010; AKINSANYA, 1976).

O Pan-africanismo do qual Nkrumah era adepto foi um movimento político e cultural que agrupava em um único conjunto a África, os africanos e os seus descendentes localizados em outros continentes, e que tinha como grandes objetivos promover a unificação africana e a solidariedade entre a sua população. O discurso Pan-africanista, nesse sentido, afirmava a homogeneidade do povo africano que, por isso, poderia constituir uma união política para si. Embora essa concepção unitária desconsiderasse a pluralidade de identidades que caracteriza a África, ela foi utilizada por Nkrumah para defender a formação da União dos Estados Africanos que seria caracterizada por uma plena integração política entre os países que a constituiriam (ASANTE; CHANAIWA, 2010; APPIAH, 1997).

Embora Nkrumah tenha muitas vezes mobilizado a noção de homogeneidade identitária africana em termos de raça, conclamando a unidade de ação dos povos colonizados devido ao fato de serem explorados pelos europeus por serem negros (FALOLA, 2001), ele também reconheceu a pluralidade cultural da África. Dedicando o livro Consciencism: Filosofia e Ideologia para a descolonização para abordar esse tema, o presidente de Gana afirmou que a África precisava harmonizar as três correntes culturais que a caracterizava, a saber, a tradicional africana, a cristãeuropeia e a islâmica, que deveriam ser exploradas em prol do desenvolvimento e do crescimento harmonioso do continente (NKRUMAH, 1964).

Observa-se nessa ideia de três correntes culturais uma resposta de Nkrumah aos círculos concêntricos de Nasser: enquanto este restringiu a África a um único círculo e tentou impedir a vinculação do continente com os círculos árabe e muçulmano, o presidente de Gana reconheceu a pluralidade dos elementos que caracterizam o continente e afirmou que não se pode descartar as heranças de cada uma das correntes na composição da identidade africana. Mesmo tendo generalizado a concepção de tal identidade, sua afirmação a esse respeito se chocou com a de Nasser e buscou deslegitimar as suas tentativas de atribuir ao Egito uma excepcionalidade identitária que justificasse sua liderança no continente.

Os modos como os presidentes do Egito e de Gana se lançaram como líderes do continente, portanto, se diferem. Enquanto Nasser usou o argumento da superioridade egípcia, Nkrumah elegeu Gana como um dos níveis nos quais a Revolução Africana aconteceria. O primeiro nível seria o individual; posteriormente, as transformações que se sucederiam em Gana representariam o nível subsistêmico para, por fim, o nível sistêmico do continente africano ser atingido. A liberdade em um 
ambiente estável que permitisse a livre expressão das pessoas eram as condições da primeira etapa. As mudanças individuais se desdobrariam para o nível subsistêmico e fariam com que as ações dos ganeses eliminassem o sistema colonial e o substituíssem por uma estrutura condizente com os desejos nacionais. Espelhando-se em Gana, todo o sistema africano poderia ser, dessa forma, transformado (DODOO, 2012). Nasser foi bem menos específico na sua concepção sobre a revolução: para ele, os países colonizados passariam por uma transformação política para conquistarem sua independência e, posteriormente, por uma revolução social marcada pelo conflito entre as classes internas para alcançar a justiça (NASSER, 1959), não abordando as implicações dessas mudanças locais para o continente.

A Revolução Africana idealizada por Nkrumah seria o processo que expulsaria os colonizadores, devolveria a liberdade aos povos africanos e promoveria a sua união e a sua integração política, ideias centrais no Movimento Pan-africanista. Tal integração seguiria cinco etapas, a saber, a criação de uma área de livre comércio, de uma união aduaneira, de um mercado comum, de uma união econômica e, por fim, de uma união política. Esta união deveria criar, aos olhos de Nkrumah, a coordenação continental para todos os temas políticos, a adoção de um padrão nas estratégias militares e de defesa, e uma política externa comum (DODOO, 2012).

Assim como Nasser, Nkrumah denunciava claramente as práticas neocolonialistas e imperialistas na África. Deve-se ressaltar, porém, que o líder ganês condenava todos os agentes nelas envolvidos, reconhecendo que as próprias elites africanas eram coniventes com os dominadores econômicos externos devido aos ganhos particulares que buscavam adquirir. Definindo o neocolonialismo como um controle externo exercido sobre países teoricamente independentes, Nkrumah expressou sua revolta contra todos os seus agentes, conforme pode-se observar no seguinte trecho de seu livro Neocolonialismo: o último estágio do imperialismo:

\footnotetext{
Empresas americanas e europeias conectadas com as maiores e mais poderosas instituições financeiras do mundo estão, com o consentimento dos governos africanos, executando grandes projetos desenhados para explorar novas fontes como produtos primários. [...] A África não obteve muito êxito no percurso para promover o desenvolvimento industrial porque seus recursos naturais não têm sido empregados para esse fim, mas têm sido usados para o maior desenvolvimento do mundo ocidental. (NKRUMAH, 1967, p. 84, tradução nossa, grifo nosso) ${ }^{7}$.
}

7American and European companies connected with the world's most powerful banking and financial institutions are, with the consent of African governments, entering upon major projects designed to exploit new sources of primary products. [...] Africa has failed to make much headway on the road to purposeful industrial development because her natural resources have not been employed for that end but have been used for the greater development of the Western world. 
Percebe-se, desse modo, que tanto Nasser quanto Nkrumah buscaram se projetar como lideranças políticas na África e que, embora compartilhassem de alguns objetivos, cada um deles mobilizou justificativas diferentes para tentar exercer esse papel. Ambos enxergaram na OUA um espaço propício não apenas para expressar aos demais países africanos os seus ideais, mas também para conquistar o seu apoio para causas bastante específicas. A OUA foi, nesse sentido, palco da disputa entre os dois presidentes, canal de expressão das desigualdades internacionais e espaço de construção de um melhor cenário interno e externo para a África.

\section{A OUA nos sistemas regional e internacional: parcerias e reivindicações}

Os temas de interesse geral entre os membros da OUA que foram afirmados ao longo das cúpulas aqui consideradas foram os seguintes: denúncia do colonialismo e da interferência externa na África; pedidos pela total e completa independência do continente; apoio aos movimentos nacionalistas; condenação do apartheid na África do Sul e de sua postura colonialista no continente; clamores pelo fim da corrida armamentista e da posse de armas nucleares; preocupações com os padrões sociais e de saúde vigentes na África; busca de uma posição comum entre os membros da OUA na ONU e a afirmação de que esta organização deveria possuir um critério justo de representação no Conselho de Segurança; apontamento da necessidade de reestruturar o comércio internacional para que ele se tornasse mais justo com os países africanos; condenação da segregação nos EUA; preocupação com conflitos e com a situação dos refugiados no continente; destaque da importância das candidaturas dos países africanos nas agências da ONU; ênfase na atuação africana nos processos de desenvolvimento de melhores padrões sociais e de modernização através de pesquisas realizadas no próprio continente; afirmação da importância da participação dos jovens no desenvolvimento da África; e, por fim, a recomendação de que o sistema educacional dos países africanos se modificasse para fornecer uma educação que fosse capaz de transmitir a realidade do continente ${ }^{8}$.

Em se tratando dos interesses mais diretos de Gana, é importante destacar que a própria OUA era algo distinto do projeto integracionista defendido por Nkrumah. A rejeição à sua proposta ambiciosa de união política pelos membros do Grupo de Monróvia teve maior apelo no continente bem como a defesa desse grupo de manter as fronteiras coloniais após a independência e que consta

8 As informações desse parágrafo foram obtidas nas declarações das cúpulas de chefes de Estado da OUA realizadas nas seguintes datas e localidades: Etiópia, 1963; República Árabe Unida, 1964; Gana, 1965; Etiópia, 1966; República do Congo, 1967; Argélia, 1968; Etiópia, 1969, 1970 e 1971; Marrocos, 1972; Etiópia, 1973; Uganda, 1975 e Maurício, 1976. Não houve cúpula em 1974. As referências bibliográficas finais incluem todas essas declarações. 
na declaração do Cairo (ORGANIZATION OF AFRICAN UNITY, 1964) -, mas mesmo assim o presidente ganês buscou avançar com o seu projeto de integração. Na cúpula de 1963 na Etiópia, foi afirmada a importância de se estabelecer uma união econômica baseada no livre comércio entre os países africanos (ORGANIZATION OF AFRICAN UNITY, 1963); já na cúpula seguinte, no Egito, a proposta feita por Gana de instituir uma união política foi apresentada e ficou acordado que ela seria estudada por comissões especializadas da OUA (ORGANIZATION OF AFRICAN UNITY, 1964). Ao que tudo indica, as duas propostas não avançaram muito: o tema da união política sequer apareceu nas declarações das cúpulas subsequentes e a defesa de uma integração econômica se mostrou frágil na medida em que as economias africanas eram - e ainda são - em grande medida voltadas para a exportação de bens primários, ou seja, o livre comércio entre tais bens não ofereceria vantagens tão grandes a ponto de se estabelecer uma união econômica (AKINSANYA, 1976).

Uma questão que também deve ser apontada a respeito da integração econômica na África é a ameaça que ela gera para os seus governantes. Por intermédio das barreiras ao comércio e às transações financeiras, as elites políticas e econômicas obtêm grandes quantias de dinheiro através do pagamento de impostos, fazendo com que essa renda seja uma das principais fontes de manutenção dos governos africanos e que, portanto, propostas de liberação comerciais sejam pouco atraentes (APPIAH, 1997). Destaca-se, nesse sentido, tanto a diversidade de opiniões e de interesses entre as elites africanas, a despeito das experiências comuns que tiveram, quanto a responsabilidade delas no desempenho econômico local, algo que os adeptos do chamado discurso de vitimização muitas vezes não reconhecem (FALOLA, 2001; MBEMBE, 2001).

O mal desempenho econômico da África é atribuído pelos defensores do referido discurso aos colonizadores ou às desigualdades do comércio internacional. Segundo eles, os europeus apenas exploraram o continente e não contribuíram com o seu desenvolvimento, restringindo a produção agrícola de seus países a um único produto e não promovendo sua industrialização. Ao mesmo tempo, os agentes do neocolonialismo impossibilitam a inserção econômica e financeira internacional africana em condições favoráveis, tornando a África uma refém dos interesses de governos estrangeiros e de empresas multinacionais (FALOLA, 2001).

Contudo, embora as elites africanas não possam mudar o passado colonial ou transformar completamente o sistema internacional, elas podem alterar as dinâmicas internas dos seus países em alguma medida para promoverem avanços (FALOLA, 2001). Cientes disso, muitas dessas elites africanas aderem ao discurso de vitimização para se eximirem da sua responsabilidade perante os 
problemas que atingem os seus Estados. Nesse sentido, tal discurso - que não é completamente equivocado, mas sim estrategicamente explorado - veicula a percepção de que os problemas que ocorrem na África são consequências de uma história que lhe foi imposta e ignora todas as possibilidades que as lideranças locais possuem de realizar escolhas políticas e econômicas. Esse raciocínio foi e ainda é utilizado por muitos líderes africanos para justificar a má gestão dos recursos financeiros, o uso da violência para fins políticos e a manutenção de seus governos autoritários na medida em que, na sua ausência, o caos em seus países seria maior devido às disputas internas entre os diversos grupos (MBEMBE, 2001). Vale ressaltar que muitas dessas acusações são aplicáveis a Nasser e a Nkrumah.

Retornando à discussão sobre a rivalidade entre ambos, são emblemáticas duas declarações realizadas na cúpula de Gana em 1965. A partir da percepção de que o presidente ganês também desejava ser uma liderança na África, Nasser buscou formas de deslegitimá-lo perante os demais países da OUA. Porém, sua atuação na organização, centrada na denúncia do imperialismo de Israel no Oriente Médio e na tentativa de conseguir o apoio dos países africanos a essa causa, gerou as percepções entre as demais lideranças de que o Egito estava tentando apenas conquistar aliados políticos para uma questão de interesse local e de que o país não era comprometido com os ideais da OUA. Ao longo das cúpulas da organização, o Egito mudou de tom e não atribuiu mais tanta centralidade ao seu problema com Israel, mas sua reputação na OUA já havia sofrido alguns danos. Para tentar deslegitimar Nkrumah e recuperar a sua própria imagem, Nasser tentou agir também fora da OUA e usou a Rádio Cairo como instrumento de propaganda contra o presidente de Gana, acusando-o de cooperar com o governo israelense (AKINSANYA, 1976). Como resultado direto dessa rivalidade, a declaração da cúpula de Gana de 1965 condenou as tentativas de subversão da OUA realizadas por países africanos e não africanos, bem como o uso de rádios nacionais para efetuar propagandas contra membros da organização (ORGANIZATION OF AFRICAN UNITY, 1965).

Em 1967, porém, Israel atacou o Egito e ocupou a Península do Sinai em resposta às crescentes tensões na sua relação com os Estados árabes do Oriente Médio. A partir de então, a OUA não pôde mais ignorar o problema da relação entre os dois países em conflito porque um de seus membros estava com parte de seu território ocupado em uma clara afronta à sua soberania, questões que a organização condenava em sua Carta. A declaração da cúpula da OUA no Congo no mesmo ano, portanto, condenou a ocupação estrangeira do território egípcio e afirmou que seus membros coordenariam suas ações na ONU para pressionar Israel a se retirar do Egito. Vale 
ressaltar que essa questão foi a última abordada pela declaração e não atacou diretamente o governo israelense, já que condenou a presença de tropas estrangeiras, sem especificar sua nacionalidade (ORGANIZATION OF AFRICAN UNITY, 1967). Essa postura foi o resultado tanto do desejo dos países africanos de manterem os laços de cooperação econômica e financeira com Israel quanto de crítica ao Egito por ter focalizado sua inserção na África na busca por parceiros contra o seu arquiinimigo na época (AKINSANYA, 1976).

O tom da denúncia da OUA à ocupação do Egito, entretanto, foi mudando ao longo das demais cúpulas. A crítica mais dura a Israel foi realizada no encontro de 1969 na Etiópia, quando a OUA se referiu diretamente a este país ao condenar a ocupação do território egípcio e fez um apelo à sua consciência humanitária para poupar o continente que já havia sofrido muito com a invasão de forças externas e com conflitos que trouxeram consequências negativas para a África e para o resto do mundo (ORGANIZATION OF AFRICAN UNITY, 1969). Essa mudança no modo como a OUA passou a condenar a ocupação do Egito por Israel está relacionada tanto à reorientação da postura daquele perante os países africanos no sentido de não tornar sua inserção no continente exclusivamente ligada aos seus problemas no Oriente Médio, quanto por uma diminuição da cooperação israelense para a África em decorrência das críticas feitas por seus membros na ONU à ocupação da Península do Sinai. Ademais, o início de uma cooperação financeira mais estreita com os ricos países árabes petroleiros também é apontado como um fator que levou à uma postura mais crítica da OUA perante Israel (AKINSANYA, 1976).

A partir de então, pode-se afirmar que a OUA aderiu à causa egípcia de lutar contra Israel: a organização foi enfática ao condenar a prisão de dois civis argelinos no país; destacou o papel do Egito em promover uma paz justa e duradoura no Oriente Médio; condenou veementemente a postura israelense de sequer receber o Comitê dos Dez estabelecido pela organização para tentar encontrar uma solução pacífica para o conflito; solicitou um boicote internacional a Israel; decidiu acompanhar de perto a situação no Oriente Médio; declarou que o tempo de ocupação do território egípcio por Israel não daria a este nenhum direito sobre ele; solicitou que os membros rotativos da África no Conselho de Segurança da ONU apresentassem o problema da ocupação do Egito nas reuniões; afirmou que Israel estava ocupando o coração do mundo árabe e africano ${ }^{9}$; declarou seu apoio à Palestina ${ }^{10}$ e condenou a agressão de Israel a Uganda,

9 Serra Leoa, Senegal e Libéria apresentaram reservas contra essa posição, enquanto que o Zaire manifestou sua oposição a ela.

10 Além de Gana, os mesmos países da nota acima apresentaram reservas contra esse apoio. O Zaire manteve a sua oposição. 
enxergando nesse ato uma resposta israelense à posição da OUA contra a ocupação do Sinai ${ }^{11}$.

Em 1979, com a assinatura dos Acordos de Camp David - mediados pelos Estados Unidos - Israel retirou suas tropas da Península do Sinai e dos demais territórios que havia ocupado. Considerar que a ação da OUA para intermediar esse conflito tenha sido ineficiente seria equivocado: outros atores e outras organizações estavam envolvidos na questão - a Liga Árabe e os próprios EUA - e uma solução deveria passar por todos eles. O importante a ser destacado é que a organização buscou influenciar a resolução do conflito, exercendo um papel de agência nesse sentido, condenando no âmbito internacional a postura de Israel e, consequentemente, informando aos EUA de que o país não teria seu apoio se continuasse fechando os olhos para a ação expansionista israelense no continente.

Por fim, vale ressaltar que, apesar de suas limitações - tais como a incapacidade de evitar conflitos entre países africanos, os poucos recursos materiais e até mesmo o baixo comparecimento das delegações nas cúpulas-, a OUA conseguiu atender a muitas de suas aspirações iniciais. Como exemplo pode-se citar a reforma do Conselho de Segurança para a participação mais equitativa dos países africanos e o convite feito pela ONU para a OUA participar de suas atividades (ORGANIZATION OF AFRICAN UNITY, 1965). Tão importante quanto essas conquistas é a mensagem que a OUA transmitiu para o mundo desenvolvido, ou seja, de que não se poderia mais negligenciar a relevância do continente ou privá-lo de ganhos políticos e econômicos, embora essa mensagem tenda a desconsiderar a responsabilidade das próprias elites africanas em muitos dos problemas locais. Talvez o maior indício de que a mensagem tenha sido recebida foi o fato do ganês Kofi Annan ter ocupado o cargo de Secretário Geral da ONU de 1997 a 2006, indicado pelo antigo ocupante do mesmo cargo Boutros Boutros-Ghali do Egito (GHANA IN THE COMITY, 2006).

\section{Considerações finais}

Egito e Gana disputaram a liderança da África no âmbito da OUA e ambos obtiveram ganhos e sofreram perdas. Nkrumah teve que aceitar que sua proposta integracionista era ambiciosa demais na visão dos outros países africanos, mas conseguiu lançar Gana como uma liderança no continente e como um bloqueio às aspirações de Nasser. Este, por sua vez, acompanhou a forte presença israelense na África sem conseguir revertê-la até que o Egito foi invadido por suas tropas,

11 As informações desse parágrafo foram obtidas nas declarações da cúpula dos chefes de Estado da OUA realizadas nas seguintes datas e localidades: Etiópia, 1970 e 1971; Marrocos, 1972; Etiópia, 1973; Uganda, 1975 e Maurício, 1973. As referências bibliográficas finais incluem todas as declarações. 
o que obrigava uma resposta da OUA, e até que os seus membros se interessaram cada vez mais pela cooperação afro-árabe em detrimento de Israel. Percebe-se, portanto, que os dois presidentes reconheceram a importância cada vez maior que a África estava adquirindo e que a sua posição no sistema internacional seria favorecida se eles se lançassem como as lideranças dos vários países africanos que passaram a conquistar a independência.

Uma análise menos cuidadosa poderia criticar o modo como a OUA lidou com a disputa entre Egito e Gana e o conflito entre aquele e Israel no sentido de que não houve uma forte solidariedade entre seus membros que, a despeito das experiências de sofrimento que vivenciaram, não conseguiam resolver suas disputas internas ou se solidarizarem imediatamente com a situação egípcia. Entretanto, deve-se ressaltar que a OUA foi um espaço de expressão dos diferentes interesses das elites políticas africanas que não são obrigatoriamente homogêneos: ao contrário, a diversidade de interesses políticos é benéfica para a construção de canais de cooperação e a OUA, assim como qualquer outra organização continental, foi palco da formação de alianças que se transformavam ao longo do tempo com a emergência de novos atores e de novos interesses.

As divergências mostram, portanto, que, como em outros contextos e locais com questões políticas em disputa, as lideranças africanas discordavam entre si e mobilizavam diferentes argumentos para justificar sua preponderância, como no caso dos círculos concêntricos de Nasser e da atribuição de Gana como um dos níveis da Revolução Africana feita por Nkrumah. Desse modo, tanto o embate entre Egito e Gana quanto a análise mais geral das declarações da OUA evidenciam o papel da agência africana no tratamento de problemas internacionais ou dos próprios países africanos. Por meio da OUA, a África mostrou ao mundo a sua importância política no pósindependência e, por intermédio da disputa entre Egito e Gana, foi possível constatar que a relevância do continente valia os custos de travar uma disputa pela sua liderança.

O que fica evidente ao longo da análise das cúpulas da OUA é que a África não deve ser considerada como um continente eternamente submisso ao seu legado histórico e às condições desiguais de atuação internacional. Ao contrário, a história nos mostra que desde que as primeiras independências foram conquistadas, houve uma grande articulação no continente com o objetivo de criar oportunidades de inserção mais justas para os países africanos, em um forte tom de denúncia contra sua exploração pelo mundo desenvolvido, e de alerta no sentido de que eles estavam se lançando como atores no sistema internacional e que a recusa em aceitar isso ou em ouvir as suas reivindicações poderia gerar perdas políticas.

Nesse sentido, a OUA foi capaz de propagar um projeto político que expressava 
preocupações regionais e mundiais, mas que, acima de tudo, afirmou a capacidade de ação da África no contexto internacional - mesmo que em tom de crítica - e a sua relevância geopolítica.

Mesmo que a OUA tenha tido suas limitações - e a pouca responsabilização das lideranças africanas pelos problemas locais é uma delas -, ela foi, nesse sentido, um importante veiculador do projeto político continental no pós-independência cujo alcance pode ser observado hoje na presença garantida dos países africanos nas principais instâncias internacionais, chegando até mesmo a liderá-las.

\section{Referências Bibliográficas}

AKINSANYA, A. The Afro-Arab Alliance: Dream or Reality. African Affairs, v. 75, n. 301, p. 511529, 1976. Disponível em: <http://www.jstor.org/stable/721269?seq=1\&cid=pdfreference\#references_tab_contents>. Acesso em 07 nov. 2015.

APPIAH, K. A. A invenção da África. In: APPIAH, K. A. Na casa de meu pai: a África na filosofia da cultura. Tradução de Vera Ribeiro. Rio de Janeiro: Contraponto, 1997. Cap. 1, p. 19-52.

APPIAH, K. A. O mito de um mundo africano. In: APPIAH, K. A. Na casa de meu pai: a África na filosofia da cultura. Tradução de Vera Ribeiro. Rio de Janeiro: Contraponto, 1997. Cap. 4, p. 111-126.

APPIAH, K. A. Estados alterados. In: APPIAH, K. A. Na casa de meu pai: a África na filosofia da cultura. Tradução de Vera Ribeiro. Rio de Janeiro: Contraponto, 1997. Cap. 8, p. 221-240.

APPIAH, K. A. Identidades africanas. In: APPIAH, K. A. Na casa de meu pai: a África na filosofia da cultura. Tradução de Vera Ribeiro. Rio de Janeiro: Contraponto, 1997. Cap. 9, p. 241252.

ASANTE, S. K. B.; CHANAIWA, D. História Geral da África: África desde 1935. Brasília: UNESCO, 2010. (O Pan-africanismo e a Integração Regional, 24).

DOBRONRAVINE, N. "O Islã na África do Oeste e no Brasil". Ciclo de Palestras da Casa das Áfricas, Salvador/São Paulo: Casa das Áfricas/UFBA/CEDIC, p. 1-46, 2003. Disponível em: $\quad<$ http://www.casadasafricas.org.br/wp/wp-content/uploads/2011/08/O-Isla-na-Africado-Oeste-e-no-Brasil.pdf>. Acesso em: 10 nov. 2015.

DODOO, V. Kwame Nkrumah's Mission and Vision for Africa and the World. The Journal of Pan African Studies, v. 4, n. 10, p. 78-92, 2012. Disponível em: $<$ http://www.jpanafrican.org/docs/vol4no10/4.10KwameNkrumah.pdf>. Acesso em: 28 nov. 2015.

DÖPCKE, W. Sai a Organização de Unidade Africana - entra a União Africana: novas encenações do continentalismo africano. Meridiano 47, n. 28-29, p. 1-4, 2002. Disponível em: $<$ http://repositorio.unb.br/bitstream/10482/10091/1/ARTIGO_OrganizacaoUnidadeAfrican a.pdf>. Acesso em: 08 dez. 2015. 
FALOLA, T. "Seek Ye the Political Kingdom": Nationalism and Nation Building. In: FALOLA, T. Nationalism and African Intellectuals. Rochester, New York: University of Rochester Press, 2001. Cap. 3, p. 97-142.

FALOLA, T. From Repatriation to Reparation: Old and New Pan-Africanism. In: FALOLA, T. Nationalism and African Intellectuals. Rochester, New York: University of Rochester Press, 2001. Cap. 4, p. 143-180.

GHANA IN THE COMITY. Ghana in the Comity of the Nations, 2006. Disponível em: $<$ http://ghanadistricts.com/home/?_=49\&sa=4768\&ssa=796>. Acesso em: 07 dez. 2015.

HATEM, M. Why and How Should Middle East and African Studies Be Connected? International Journal of Middle East Studies, v. 41, n. 2, p. 189-192, 2009. Disponível em: $<$ http://journals.cambridge.org/download.php?file=\%2FMES

\%2FMES41_02\%2FS002074380909059Xa.pdf\&code=304bed85f245de88be3d4e84592eb dd3>. Acesso em: 18 nov. 2015.

KODJO, E.; CHANAIWA, D. História Geral da África: África desde 1935. Brasília: UNESCO, 2010. (Pan-africanismo e libertação, 25).

ORGANIZATION OF AFRICAN UNITY. Resolutions adopted by the first conference of independent African Heads of State and Government held in Addis Ababa, Ethiopia, from 22 to 25 may 1963. Addis Abeba, 1963.

ORGANIZATION OF AFRICAN UNITY. Resolutions adopted by the first ordinary session of the assembly of Heads of State and Government held in Cairo, UAR, from 17 to 21 july 1964, Addis Abeba, 1964.

ORGANIZATION OF AFRICAN UNITY. Resolutions adopted by the second ordinary session of the assembly of Heads of State and Government held in Accra, Ghana from 21 to 26 october 1965, Addis Abeba, 1965.

ORGANIZATION OF AFRICAN UNITY. Resolutions adopted by the third ordinary session of the assembly of heads of state and government held in Addis Ababa, Ethiopia, from 5 to 9 november 1966, Addis Abeba, 1966.

ORGANIZATION OF AFRICAN UNITY. Resolutions and declarations adopted by the fourth ordinary session of the assembly of Heads of State and Government held in Kinshasa, Congo, from 11 to 14 september 1967, Addis Abeba, 1967.

ORGANIZATION OF AFRICAN UNITY. Resolutions adopte by the fifth ordinary session of the assembly of Heads of State and Government held in Algiers, from 13 to 16 september 1968, Addis Abeba, 1968.

ORGANIZATION OF AFRICAN UNITY. Resolutions adopted by the sixth ordinary session of the assembly of Heads of State and Government held in Addis Ababa from 6 to 10 september 1969, Addis Abeba, 1969. 
ORGANIZATION OF AFRICAN UNITY. Resolutions adopted by the seventh ordinary session of the assembly of Heads of State and Government held in Addis Ababa from 1 to 3 september 1970, Addis Abeba, 1970.

ORGANIZATION OF AFRICAN UNITY. Resolutions adopted by the seventh ordinary session of the assembly of Heads of State and Government held in Addis Ababa from 21 to 23 june 1971, Addis Abeba, 1971.

ORGANIZATION OF AFRICAN UNITY. Resolutions adopted by the eigth ordinary session of the assembly of Heads of State and Government held in Rabat from 12 to 15 june 1972, Addis Abeba, 1972.

ORGANIZATION OF AFRICAN UNITY. Resolutions adopted by the assembly of Heads of State and Government in its tenth ordinary session, Addis Abeba, 1973.

ORGANIZATION OF AFRICAN UNITY. Resolutions adopted by the assembly of Heads of State and Government, Addis Abeba, 1975.

ORGANIZATION OF AFRICAN UNITY. Resolutions of the thirteenth ordinary session of the assembly of Head of State and Govenment, Addis Abeba, 1976.

MBEMBE, A. As Formas Africanas de Auto-Inscrição. Estudos Afro-Asiáticos, ano 23, n. 1, p. 171209, 2001. Disponível em: <http://www.scielo.br/pdf/eaa/v23n1/a07v23n1.pdf>. Acesso em 25 nov. 2015.

NASSER, G. A. The Philosophy of the Revolution. Estados Unidos: Smith, Keynes \& Marshall, 1959.

NKRUMAH, K. Recursos primários e interesses externos. In: NKRUMAH, K. Neocolonialismo: o último estágio do imperialismo. Rio de Janeiro: Civilização Brasileira, 1967. Cap. 6, p. 84109.

NKRUMAH, K. Society and Ideology. In: NKRUMAH, K. Consciencism: Philosophy and ideology for de-colonization. New York: Monthly Review, 1964. Cap. 3, p. 56-77.

SOUARE, I. K. Egypt's Evolving Role in Africa: A Sub-Saharan Perspective. Institute of Diplomatic Studies, Cairo, p. 1-7, 2008. Disponível em: $<$ https://www.issafrica.org/uploads/EGYPROLEAFRICA.PDF>. Acesso em: 23 nov. 2015.

TAGELDIN, S. M. The Place of Africa, in Theory: Pan-Africanism, Postcolonialism, Beyond. Journal of Historical Sociology, v. 27, n. 3, p. 302-323, 2014. Disponível em: $<$ http://onlinelibrary.wiley.com/doi/10.1111/johs.12061/pdf $>$. Acesso em: 20 nov. 2015.

THORNTON, J. A África e os africanos na formação do mundo atlântico: 1400-1800. Rio de Janeiro: Campus, 2000.

WESTERN, W. C. Nación y poder. In: WESTERN, W. C. Alquimia de la nación: Nasserismo y 
Sankofa. Revista de História da África e de Estudos da Diáspora Africana Ano IX, NºXVII, agosto/2016 poder. México: El Colegio de México, 1997. Cap. 3, p. 77-130.

\section{Recebido em 20/02/16 - Aprovado em 07/07/16}

